\title{
INOCULATION OF CONTAMINATED SUBSURFACE SOILS WITH ENRICHED INDIGENOUS MICROBES TO ENHANCE BIOREMEDIATION RATES
}

\author{
W. J. WEBER JR and H, X. CORSEUIL ${ }^{2}$ \\ 'Department of Civil and Environmental Engineering, The University of Michigan, Ann Arbor, \\ MI 48109, U.S.A. and ' Departamento de Engenharia Sanitária, Universidade Federal de Santa Catarina, \\ Florianópolis, SC 88039, Brazil
}

(First received January 1993; accepted in revised form September 1993)

\begin{abstract}
The inoculation of subsurface soils with enriched indigenous microbes to enhance bioremediation is described. The technique, designed to rapidly increase subsurface populations of specific microorganisms, is tested in laboratory soil columns using benzene, toluene and xylene as organic target compounds and a natural aquifer sand as a subsurface medium. A short biologically active carbon adsorber is demonstrated to be an efficient reactor system for the growth, acclimation and enrichment of indigeous microorganisms for re-inoculation purposes. Empty-bed reactor contact times of approx. $40 \mathrm{~s}$ are shown to be sufficient for continuous production of effluent streams of enriched indigenous microbes for re-inoculation. The ability of the technique to rapidly increase populations of such microbes to levels above $10^{5}$ cells $\mathrm{g}^{-1}$ of dry solids in the previously uncontaminated aquifer sand studied is shown to result in enhanced rates of in situ degradation of the target hydrocarbons over a broad range of concentrations, from 25 to $9000 \mu \mathrm{g} \mathrm{1}^{-1}$.
\end{abstract}

Key words-bioremediation, bioaugmentation, groundwater, biological activated carbon, re-inoculation, soils, biodegradation, monoaromatic hydrocarbons

\section{INTRODUCTION}

Processes for removing organic contaminants from groundwaters and subsurface soil systems include adsorption by activated carbon, air stripping, chemical oxidation and biological degradation. These processes can be implemented to control the movement of plumes, treat groundwater, decontaminate soil or some combination of these objectives. Long periods of time and high costs are commonly associated with "pump-and-treat" schemes for remediation of contaminated sites. The disadvantages of such techniques relate largely to the fact that extensive amounts of groundwater must be removed and processed. On the other hand, the most cost-effective process, in situ biological degradation, is often limited by difficulties in the transport of nutrients or electron acceptors and the control of conditions for acclimation and contaminant degradation in the subsurface. Moreover, indigenous microbes, while perhaps fully capable of degrading specific contaminants, may require long periods of time before they develop sufficiently large populations to exert measurable effects on those contaminants in subsurface systems (Corseuil and Weber, 1994).

The technique described here is designed to enhance the applicability of in situ bioremediation processes by inoculation of adapted and enriched populations of indigenous microorganisms specif- cally capable of degrading target contaminants. Previous observations of success and failure with respect to the inoculation of microbes having specific metabolic capabilities have related largely to batch microcosms (Oldenhuis et al., 1989; Aamand et al., 1989; Crawford and Mohn, 1985; Edgwehill and Finn, 1983; Lehtomäki and Niemelä, 1975).

A bioaugmentation system developed by Weber and Corseuil (1991) for generation of microorganisms was employed as a source of inoculum. The system derives from earlier investigations and applications of biologically active carbon (BAC) systems for water and wastewater treatment (e.g. Weber et al., 1970, 1973). The system uses small BAC reactors in lowvolume pumping schemes for continuous growth, acclimation and enrichment of specific microorganisms for subequent sloughing and reintroduction to the subsurface. Activated carbon has been confirmed to yield much higher levels of substrate biodegradation and higher specific growth rates when used as a bio-support medium than non-adsorbing or weakly adsorbing media, such as sand ( $\mathrm{Li}$ and DiGiano, 1983). There are several other advantages that an attached growth system of this type offers over a dispersed growth system (as suggested by McCarty, 1985). First, the inoculum stream leaving the reactor contains much lower levels of suspended solids, thus requiring no filtration. Filtration of extraneous suspended solids from the effluent of a dispersed growth 
reactor would tend also to remove microbes associated with these solids. Second, the mature microbes selectively sloughed from attached growth systems are likely to be less adherent than freshly grown microorganisms, and thus more readily able to move through the porous media of subsurface systems. A third advantage is that most organic contaminants specifically targeted for bioremediation exhibit adsorption characteristics, allowing them to be retained on the activated carbon support medium employed in this type of attached growth reactor for periods much longer than the hydraulic residence or "space" times of those reactors. Natural background organic substrates, on the other hand, are generally more weakly adsorbed, and will therefore pass more readily through adsorption systems having low residence times. BAC reactors may thus facilitate selection of specific microorganisms capable of degrading target compounds because these materials are selectively retained in the reactor, and thus more readily and consistently available for microbial utilization.

The efficacy of the technique was tested initially in aquifer sand columns operated under dynamic conditions, using benzene, toluene and xylene, common monoaromatic constituents of gasoline and other hydrocarbon fuels as target compounds. The study further explored factors which affect the applicability of $\mathrm{BAC}$ reactors for inoculation of microbes, including: (i) reactor behavior in the presence of high and low concentrations of electron donors (the target compounds) and an electron acceptor (oxygen); (ii) comparative degradation rates at high (ppm) and low (ppb) contaminant concentrations in columns of aquifer sand with and without inoculation; (iii) minimum inoculant levels required to enhance biodegradation; (iv) the effectiveness of inoculum microbes grown on one compound in the monoaromatic hydrocarbon series on the degradation of another; and; (v) a preliminary assessment of how readily the inoculated microbes might move through sandy aquifer soils, an important factor for potential field scale applications of the technique.

\section{EXPERIMENTAL METHODS}

Laboratory experiments were conducted using BAC reactors containing granular activated carbon (Filtrasorb F-400) and bench-scale subsurface microcosms containing aquifer sand obtained from a natural gas production facility in Kalkaska, Mich. Benzene, toluene and xylene were used as individual substrates in various experiments. These chemicals were mixed in a synthetic background solution, as described in a preceding paper (Corseuil and Weber, 1994). The BAC reactors consisted of $1.6-\mathrm{cm}$ i.d. glass columns containing $1.0 \mathrm{~g}$ of $30 \times 40$ (US standard sieve size) granular activated carbon, corresponding to a packed bed depth of approx. $1 \mathrm{~cm}$. Prior to being packed in the columns, the carbon was immersed in Milli-Q water overnight to remove air from its pore structure. Once packed, the system was rinsed with $200 \mathrm{ml}$ of Milli-Q water to remove remaining fines. The microorganisms used to seed the carbon were obtained from columns of Kalkaska sands which previously had been fed on a continuous basis for 10 days with aqueous solutions of benzene, toluene or ortho + para-xylene as sole carbon sources. Plate count analysis of the effluents of these preparatory sand column studies indicated that different predominant species were selected naturally in the presence of each of the hydrocarbons. The predominant colonies were streaked on new plates, then grown in $0.5 \%$ tryptone nutrient broth until a cell density of about $1 \times 10^{7}$ viable cells $\mathrm{ml}^{-1}$ was obtained. One-ml samples of the viable cells were collected and passed through $0.2-\mu \mathrm{m}$ pore-size membrane filters (Gelman Co., Ann Arbor, Mich.). The microorganisms were then recovered with $1 \mathrm{ml}$ of $0.01-\mathrm{N}$ phosphate buffer solution and used to inoculate the BAC reactor. A period of at least $12 \mathrm{~h}$ was allowed for microorganisms to attach to the carbon particles before the start of an experiment. The synthetic groundwater and stock solutions of target compounds, prepared in head-space-free glass cylinders and mixed for at least $12 \mathrm{~h}$ before use, were fed to the system, using separate Rabbit-HP solvent delivery systems (Rainin Inst. Co., Woburn, Mass.). A mixing chamber (Rainin Inst. Co., Woburn, Mass.) was incorporated immediately prior to the influent port to provide adequate mixing of the target organic compounds and the background nutrient solution. The BAC systems were operated in up-flow mode to avoid potential air binding. Tests were conducted at empty bed contact times (EBCTs) of 40 and $60 \mathrm{~s}$.

The complete carbon reactor, sand column and inoculation procedure is shown schematically in Fig. 1. Preparation of the sand columns and methods of analyses have been described elsewhere by Corseuil and Weber (1994). Seeding of the aquifer sand beds was done by passing the effluent from the carbon reactor through the aquifer sand for $15 \mathrm{~h}$. Experiments were performed at room temperature and an interstitial velocity of $2 \mathrm{~m} \mathrm{~d}^{-1}$. Two columns were inoculated in parallel to determine the initial mass of specific microbes attached on the aquifer sands. One of the columns was then taken apart, and microorganisms attached to solids at the bottom and the top of the column enumerated. Inoculation was performed after a steady-state condition of cell growth and sloughing had been achieved in the carbon reactor. The effluent from this reactor was stripped continuously with air during the inoculation period to prevent hydrocarbon contamination of the sand columns.

\section{RESULTS}

Experiments with the BAC systems were performed using short empty bed contact times to verify the feasibility of employing small reactors for growth and enrichment of indigenous microorganisms. The capability of specific microorganisms was initially investigated under limiting oxygen conditions. As illustrated in Fig. 2, results obtained from a BAC reactor fed with a solution containing $10 \mathrm{mg} \mathrm{l}^{-1}$ toluene and $8.7 \mathrm{mg} \mathrm{l}^{-1}$ dissolved oxygen show that, even with a residence time of only $40 \mathrm{~s}$, all oxygen provided in the influent stream was utilized by toluene degraders after 10,000 bed volumes (approx. 4.6 days). At this stage, a limited (50\%) level of toluene degradation was reached because of limited electron acceptor conditions. Plate count measurements at this point revealed that an average $6 \times 10^{6}{\text { cells } \mathrm{ml}^{-1}}^{-1}$ were being detached from the reactor, providing a continuous source of pre-adapted microbes for inoculation and bioaugmentation purposes.

Another study was performed with the same reactor to test the opposite extreme conditions; i.e. very low influent concentrations of electron donor and 


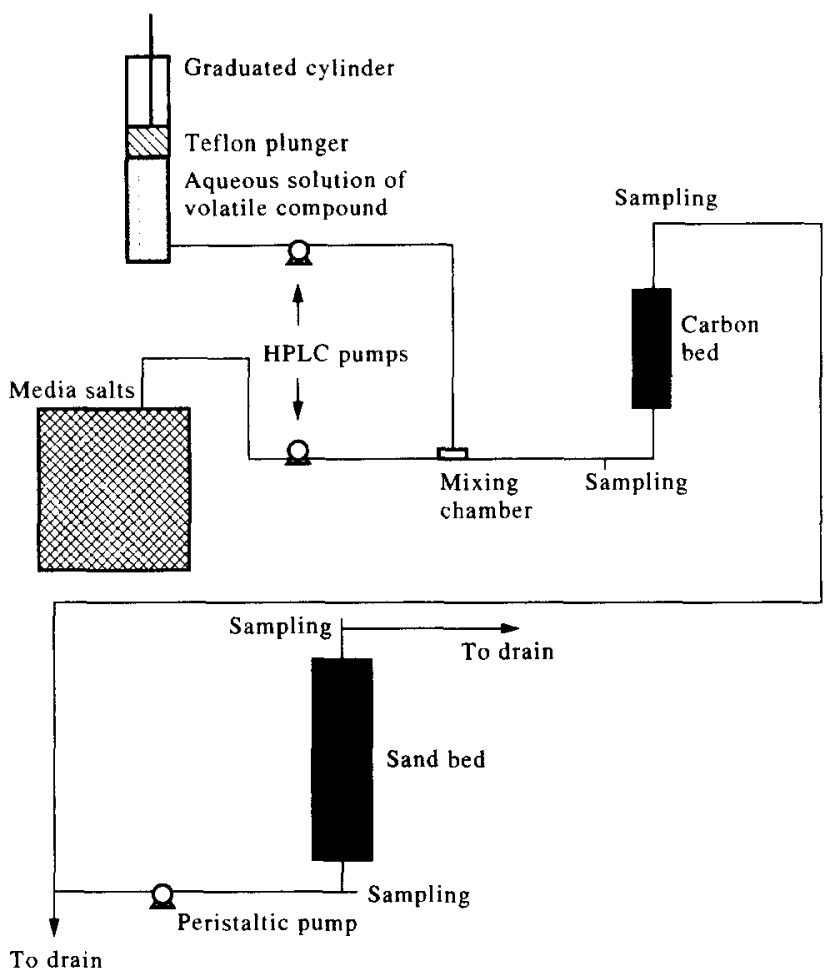

Fig. 1. A schematic illustration of the integrated experimental inoculation system.

electron acceptor, $0.095 \mathrm{mg}^{-1}$ benzene and $0.7 \mathrm{mg}$ $1^{-1}$ dissolved oxygen. This is reasonably typical of downgradient conditions commonly found in groundwaters contaminated by gasoline spills. After an initial stage ( $\sim 5000$ bed volumes) during which adsorption functioned as the primary mechanism of removal, the concentration of benzene in the effluent from the carbon system reached a plateau of about $0.04 \mathrm{mg} \mathrm{l}^{-1}$, and then decreased to a steady-state level of approx. $0.02 \mathrm{mg} \mathrm{l}^{-1}$, with a concomitant increase of biomass in the reactor due to microbial growth. At this point, microbial counts indicated that the effluent from the reactor contained approx. $10^{5}$ cells $\mathrm{ml}^{-1}$. In this experiment, dissolved oxygen consumption was not measured because the microbes required such small amounts of oxygen (less than $0.2 \mathrm{mg} \mathrm{l}^{-1}$ ) to metabolize the low benzene influent concentration.

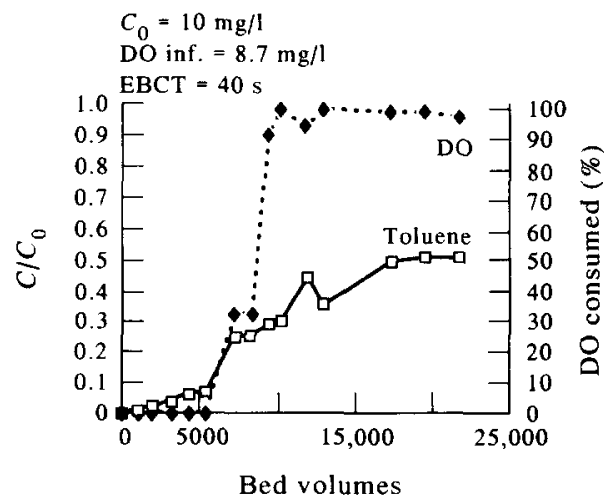

Fig. 2. Substrate breakthrough and oxygen consumption patterns for toluene in the $\mathrm{BAC}$ reactor system.
An attempt was made to test whether the low oxygen concentrations limited benzene degradation. In this test, dissolved oxygen in the influent stream was increased to $8 \mathrm{mg}^{-1}$, but no additional benzene removal was observed.

Other experiments were performed to assess the efficiency of small BAC reactors with respect to contaminant removal. This is an important consideration from the point of view that many federal and state regulations prohibit reintroduction of contaminated groundwater to aquifers, no matter how small the return flow or its primary function as a bacterial inoculum. As noted in Fig. 3, removals in excess of $99 \%$ were obtained for a reactor previously seeded with benzene degraders, fed with an influent containing $2.6 \mathrm{mg}^{-1}$ benzene and having an EBCT of $40 \mathrm{~s}$. To determine maximum removal efficiency

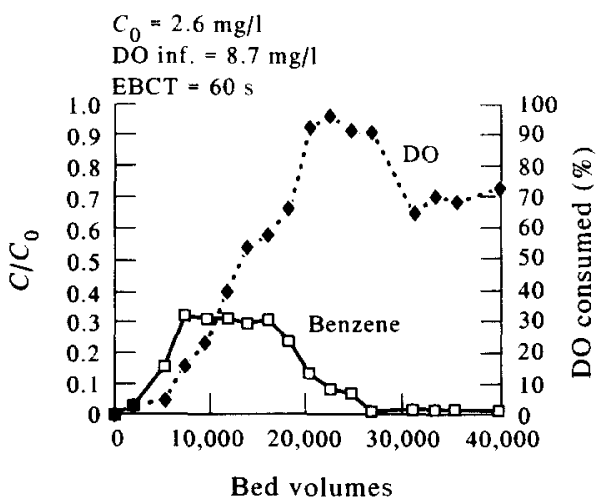

Fig. 3. Substrate breakthrough and oxygen consumption patterns for benzene in the BAC reactor system. 
for the system, experimental conditions were selected to prevent oxygen limitations. For steady-state removal of benzene, approx. $5 \times 10^{6}$ microorganisms $\mathrm{ml}^{-1}$ or about $1 \mathrm{mg}$ biomass $1^{-1}$ of specific cells were continuously sloughed from the carbon bed. It is interesting to note in Fig. 3 that oxygen consumption was higher between the points at which 17,000 and 27,000 bed volumes of contaminated water were treated than it was subsequently when steady state was reached. This is probably attributable to the release of additional benzene from the activated carbon in response to lower contaminant concentrations in the liquid phase, and the rapid degradation of this excess benzene by microbes attached to the external surfaces of the carbon.

Additional experiments using ortho + para-xylene as target compounds were performed to verify that complete removal of these somewhat more difficult to degrade monoaromatic hydrocarbons could be obtained across carbon reactors operating at small EBCTs. A total xylene concentration of $3.0 \mathrm{mg} \mathrm{1}^{-1}$ was fed to such a reactor which previously had been inoculated with xylene degraders. Complete removal was observed with an EBCT of $60 \mathrm{~s}$, as illustrated in Fig. 4, but the number of microorganisms sloughed was smaller $\left(4 \times 10^{5} \mathrm{ml}^{-1}\right)$ than that observed in the case of benzene. The higher oxygen consumption observed in the benzene experiment did not occur in the xylene experiment. The cause for this may relate to the longer time required to desorb xylene, which is more hydrophobic than benzene and thus has a lower rate of desorption (Corseuil, 1992). The isolated benzene and xylene degraders used in each of the BAC experiments were identified respectively as Arthrobacter sp. and Xanthomonas sp. by Microbial ID Inc., Newark, Del.

Column studies with previously uncontaminated Kalkaska sands were next carried out to determine the effects of inoculation on aquifer materials using carbon reactor effluents under different conditions. In these studies, the effluent of the carbon reactor was used to inject contaminant-specific microbes to aquifer sand columns for $15 \mathrm{~h}$ before introduction of contaminant streams. Results were compared with

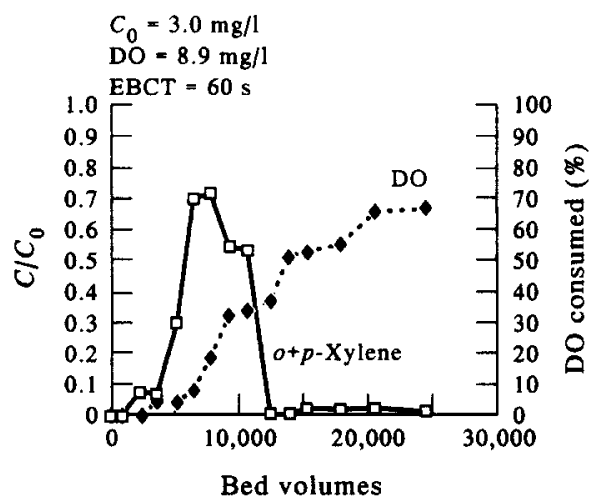

Fig. 4. Substrate breakthrough and oxygen consumption patterns for $o+p$-xylene in the BAC reactor system.

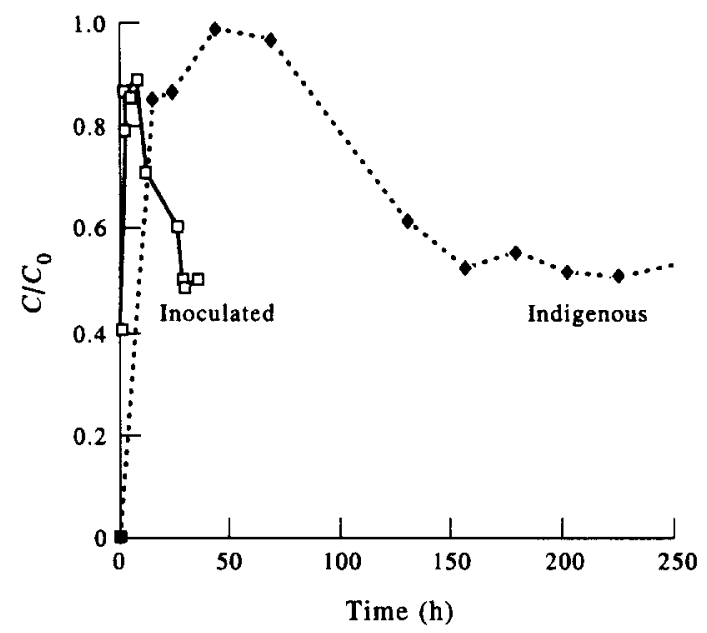

Fig. 5. Substrate breakthrough patterns for $o+p$-xylene $\left(C_{0}=9 \mathrm{mg} / \mathrm{l}\right)$ in Kalkaska sand columns containing indigenous and inoculated populations of microorganisms.

the ability of unaugmented indigenous microbial populations to degrade the target compounds, as reported by Corseuil and Weber in a companion paper (1994). In the case of high concentrations $(9 \mathrm{mg}$ $1^{-1}$ ) of benzene, the experiments showed that 12 days were required for indigenous microorganisms to utilize all oxygen supplied, after which biodegradation ceased because of insuffient electron acceptor conditions. Conversely, virtually immediate onset and continued rapid degradation was observed in experiments for which BAC-enriched benzene degraders had been previously injected into the sand columns. Within only $10 \mathrm{~h}$, complete utilization of all of the oxygen supplied continuously to the inoculated sand column was accomplished, thereby constraining further benzene degradation. Microbial counts on the aquifer sands of the inoculated column indicated that $5 \times 10^{6}$ and $3 \times 10^{6}$ cells $\mathrm{g}^{-1}$ of dry solids were attached near the bottom (influent) and the top (effluent) ends of the column, respectively. The total indigenous population attached to the Kalkaska sand was determined to be approx. $10^{4}$ cells $\mathrm{g}^{-1}$ of dry solids. Enriched inoculations thus represented a two order of magnitude increase in total numbers of contaminant-specific microbes.

Approximately 6 days were needed for the indigenous population to achieve steady-state degradation in similar experiments with $o+p$-xylene. However, as shown in Fig. 5, the same condition was obtained in only $30 \mathrm{~h}$ with columns inoculated with xylene degraders. Because the number of cells sloughed from the 1-min-EBCT reactor fed with ortho + paraxylene was smaller than that for the benzene system, the initial numbers of xylene degraders attached onto the sand near the influent and effluent ends of the column were also smaller, $4 \times 10^{5}$ and $3 \times 10^{5}$ microorganisms $\mathrm{g}^{-1}$, respectively. The fact that a longer time was required to achieve steady-state removal for xylene than for benzene may be attributable to the fact that the number of Xanthomonas sp. 
initially present in the aquifer sand was approximately one order of magnitude smaller than that of the Arthrobacter sp. involved in benzene degradation.

It has been hypothesized that microorganisms isolated from systems of high contaminant concentration may not be able to degrade organic contaminants at the significantly lower concentrations commonly found in aquifer systems and sediments (Alexander, 1985). Inoculation studies in aquatic systems with $p$-nitrophenol (PNP) have shown mineralization at concentations above $50 \mu \mathrm{g} \mathrm{l}^{-1}$, but only $35 \%$ mineralization when concentrations of PNP were $26 \mu \mathrm{g}^{-1}$ or less (Zaldi et al., 1989). To test this hypothesis, the experiments described above were repeated at low hydrocarbon concentrations. Benzene and $o$-xylene at concentration levels of $25 \mu \mathrm{g} \mathrm{l}^{-1}$ were first fed as sole carbon sources to two non-previously-exposed sand columns to test the capability of indigenous microorganisms to degrade trace levels of these hydrocarbons. Under these conditions, the indigenous populations were able to completely degrade benzene and $o$-xylene only after 12 and 7 days, respectively (Corseuil and Weber, 1994). Conversely, immediate and complete degradation was observed in otherwise identical experiments with sand columns which had been inoculated with benzene and xylene degraders sloughed from carbon reactors. The concentrations of benzene and $o$-xylene in the effluents of the inoculated sand columns were below detection limits $\left(0.1 \mu \mathrm{g} \mathrm{l}^{-1}\right)$ from the very onset of the experiments.

Interaction effects in the degradation of one aromatic hydrocarbon by microbial populations grown on another are not yet well understood (Bauer and Capone, 1988). Arvin et al. (1989) have observed that toluene and xylene degraders are able to degrade benzene only if either toluene or xylene are present singularly, but that in combinations of the three compounds stimulation effects are smaller than those for each of the compounds alone. Reasons for this behavior were not determined. Alvarez and Vogel (1991) examined such interactions and concluded that, despite the similar chemical structure of these compounds, some microorganisms may be capable of metabolizing more than one of the compounds but not necessarily all of them.

To further explore this issue, two experiments were performed to analyze the behavior of substratespecific microbes inoculated into sand columns fed by a different substrate. In the first of these experiments, benzene degraders were inoculated to a sand column to achieve an initial biomass of approx. $4 \times 10^{6}$ cells $\mathrm{g}^{-1}$ of dry solids, and a solution containing $8.2 \mathrm{mg} \mathrm{l}^{-1}$ toluene then fed to the inoculated sand column. Approximately 3 days were required before toluene degradation reached a level where it became limited by the electron acceptor (oxygen) concentration. It is noted in work reported in a companion paper (Corseuil and Weber, 1994) that the onset of measurable degradation of toluene by unaugmented indigenous microorganisms in the same aquifer soil required a critical population development (CPD) period of approx. 4 days. It thus appears that inoculation to increase microbe population is helpful even with microbes adapted to a different compound of the same general chemical class. This observation further supports a conclusion that the time required for enzyme adaptation is not significant relative to the time for critical population development as a contributor to the lag periods observed in this work.

A similar effect was noted in the second experiment, in which a sand column previously inoculated with xylene degraders was fed a $25-\mu \mathrm{g} \mathrm{I}^{-1}$ benzene solution. The results shown in Fig. 6 illustrate that complete benzene removal occurred after approx. 1 day. As mentioned above, immediate degradation was seen when sand columns were inoculated with microorganisms specifically adapted to each of the contaminants.

The feasibility of using inoculation techniques in large-scale in situ bioremediation schemes will depend ultimately on the facility with which microorganisms can migrate or be transported through aquifer solids. To explore the approximate mobility of the xylene degraders isolated from the carbon reactors, several experiments were performed in otherwise identical sand columns having lengths of $6.1,20.4$ and $101 \mathrm{~cm}$. The columns were packed with non-sterile sand, through which an autoclaved synthetic groundwater solution was then passed for $3 \mathrm{~h}$ to enumerate background effluent counts of Xanthomonas sp. The effluent stream from the carbon reactor, containing approx. $3 \times 10^{5}$ cells $\mathrm{ml}^{-1}$ sloughed continuously from the carbon, was then injected into each column at a flow rate designed to yield an interstitial velocity of $2 \mathrm{~m} \mathrm{~d}^{-1}$. Periodic plate count analyses on the influents and effluents of the columns were made to determine breakthrough profiles for the xylene

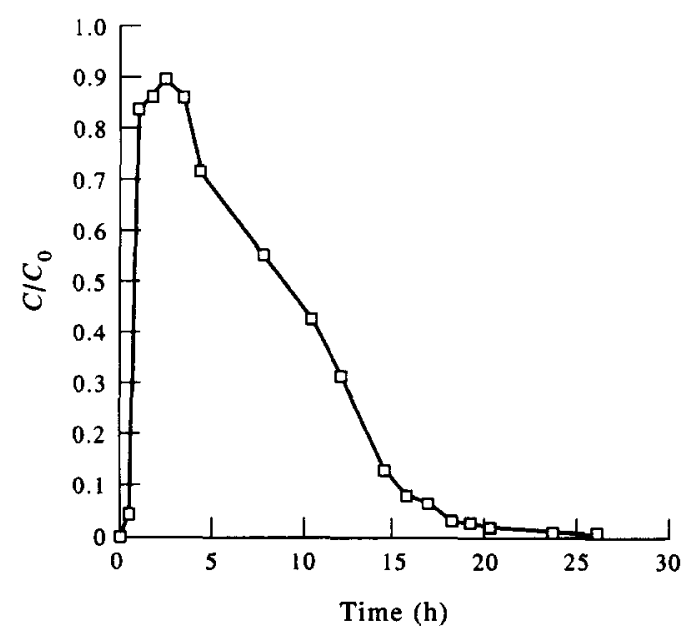

Fig. 6. Substrate breakthrough patterns for benzene $\left(C_{0}=25 \mu \mathrm{g} / \mathrm{l}\right)$ in Kalkaska sand columns after inoculation with xylene degraders. 


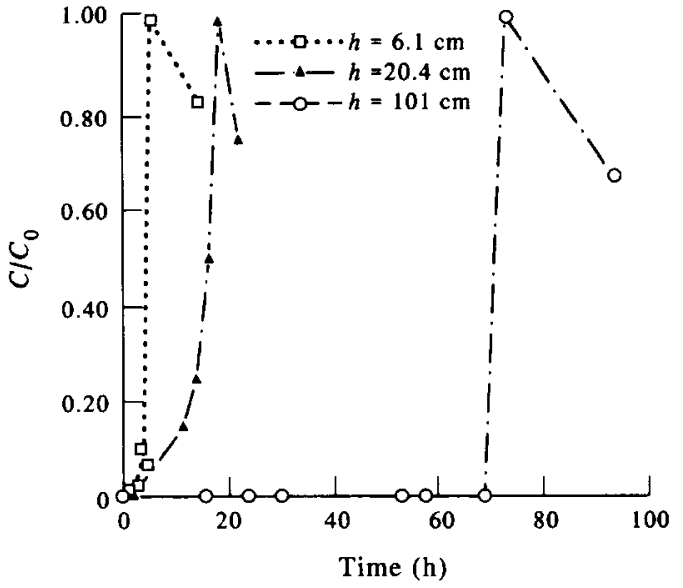

Fig. 7. Breakthrough patterns for Xanthomonas sp. in Kalkaska sand columns of different lengths.

degraders. Identification was straightforward due to the distinctive small size and bright yellow color of Xanthomonas sp. colonies formed on the plates. As illustrated in Fig. 7, the microorganisms passed through the soil columns with some facility. The ratio of the respective times required for the microorganisms and a conservative tracer (sodium chloride) to break through the sand columns was found to have an essentially constant value of about six for all columns, suggesting that the movement of microbes was independent of column length, at least for the conditions tested. The original number of Xanthomonas sp. present in the Kalkaska sands was approx. $10^{3}$ cells $\mathrm{g}^{-1}$ of dry solids. Analysis of the sand near the influent and effluent ends of the columns at the end of the experiments showed that the number of specific microbes attached to the solids varied over only a relatively narrow range, from $3 \times 10^{5}$ to $5 \times 10^{5}$ cells $\mathrm{g}^{-1}$ of dry solids. The microbes sloughed from the BAC are likely to be the most mature microbes in the attached growth reactor. This could mean that they are less sticky and less likely to adhere to surfaces than less mature organisms, which in turn might constitute an implicit advantage for attached growth reactors as inoculum sources. Freshly grown dispersed-phase cultures might tend to be more adherent in character, and thus not migrate as freely in porous media. In any event, the preliminary findings confirm qualitatively the observations of other investigators regarding the ability of contaminant-degrading microbes to migrate and be transported effectively in sandy aquifer soils (Matthess et al., 1988; Harvey et al., 1989).

\section{DISCUSSION}

Comparison of the sand column experiments with high concentrations of BTX hydrocarbons and indigenous and inoculated microorganisms illustrates the importance of inoculum size in enhancing rates of biodegradation. For benzene, an inoculationaugmented population of $4 \times 10^{6}$ cells $\mathrm{g}^{-1}$ of dry solids was shown to consume all available oxygen, the electron acceptor, after only $10 \mathrm{~h}$. Attainment of this same level of activity required 12 days when the indigenous microorganisms on the sand were not augmented by inoculation. For xylene, an order of magnitude less attached biomass $\left(4 \times 10^{5} \mathrm{~g}^{-1}\right)$ took $30 \mathrm{~h}$ to reach maximum degradation; still much faster than the 6-day period required in unaugmented aquifer solids columns containing indigenous populations. Even when the inoculations were carried out with microbes grown on a different target compound than the contaminant being tested, degradation occurred much more rapidly than in uninoculated controls, suggesting that attainment of a critical population size occurs more slowly than does enzyme adaptation.

Immediate and complete degradation was observed in inoculated sand columns fed with very low concentration solutions of the target aromatic hydrocarbons, suggesting that rapid and complete mineralization can be accomplished even under substrate limiting conditions if the density of the specific microbes is increased, in the cases studied to levels above $10^{5}$ cells $\mathrm{g}^{-1}$ of soil. Similar results have been reported from studies of inoculum sizes required for mineralization of $p$-nitrophenol in lake water (Ramadan et al., 1990), for which an initial density of about $10^{5}$ cells $\mathrm{ml}^{-1}$ was needed to prevent microbial elimination by protozoan grazing or failure to survive because of nutrient deficiencies. Unlike the experiments of Zaldi et al. (1989) with $p$-nitrophenol, benzene and xylene degraders isolated from highconcentration systems experienced no difficulty in degrading the same hydrocarbons at concentrations in the range of $25 \mu \mathrm{g} \mathrm{I}^{-1}$. Analyses by both gas and liquid chromatography revealed no by-products of the biodegradation reactions in either the high or low concentration experiments.

Preliminary studies of the transport of Xanthomonas sp. in laboratory sand columns suggest that filtration and sorption effects in sandy aquifers will retard, but not prevent, the movement of such microorganisms, at least through the Kalkaska sands examined here. A retardation factor of six was observed for these xylene degraders, which is of the same order of magnitude of retardation observed for moderately hydrophobic compounds in sandy aquifer materials. The observation that inoculation levels of only about $10^{5}$ cells $\mathrm{g}^{-1}$ of soil of specific microbes are sufficient to enhance aquifer solids degradation is encouraging with respect to potential transport. No changes in soil permeability are likely to occur if microbial populations are increased to $10^{5}-10^{6} \mathrm{~g}^{-1}$ of soil, in that this density of microbes represents approximately only ten cells for each sand particle. It must be emphasized that the transport studies carried out in this work were very preliminary. They examined only the effects of filtration and adsorption of microorganisms, and then with only one aquifer material, the Kalkaska sand. 
A model prediction presented as a hypothetical example in a companion paper (Corseuil and Weber, 1994) can be expanded upon here to illustrate the anticipated effects of employing BAC inoculation techniques to increase the number of specific microbes present in a system by three orders of magnitude. In that example, which involved a $0.2 \mathrm{mg}$ $1^{-1}$ plume of xylene contamination in a sandy aquifer, the authors estimate that 50 and $100 \%$ levels of remediation by unaugmented indigenous populations would require 2 and 4 years, respectively. Using the same biokinetic factors and modeling approach, and providing a 1000 -fold increase in the initial active biomass to $0.125 \mathrm{mg} \mathrm{l}^{-1}$ with an inoculationaugumented system, $50 \%$ of the xylene in the plume would be degraded in 3 months, and the same aquifer would be completely decontaminated in approx. 1 year.

\section{SUMMARY AND CONCLUSIONS}

The results of this study demonstrate that biologically active carbon systems provide effective means for simultaneous contaminant destruction and enrichment of specific microorganisms for subsequent inoculation of subsurface systems. The finding that BAC empty-bed residence times of less than $1 \mathrm{~min}$ are sufficient for microorganisms to degrade monoaromatic hydrocarbons indicates that remarkably small reactors can be employed for recycle water decontamination and for microorganism selection, enrichment and inoculation. Such reactors might be incorporated as small carbon canisters on individual well heads, or as small in-line units in underground recycle and circulation systems.

The inoculation technique was examined here in the context of in situ bioremediation of subsurface systems contaminated by readily degraded monoaromatic hydrocarbons. It should be effective as well in the direct biodegradation of more recalcitrant organic contaminatns in such systems, and, potentially, for cometabolic dehalogenation of chlorinated solvents, such as tetra- and tri-chloroethylenes. A BAC inoculation scheme might be used, for example, for mass culture of the strain G4 (Nelson et al., 1986), which degrades TCE and grows on substrates which are adsorbed strongly by activated carbon. The approach might also be applied effectively to enhance the degradation of contaminants contained in other types of environmental systems, such as contaminated sediments in streams, rivers, lakes and harbors. Studies to test these potential extensions of the BAC inoculation approach are currently being conducted in our laboratories.

Acknowledgements - This work was supported by Research Grant 5 P42 ES04911-03 from the National Institutes of Environmental and Health Sciences, by Research Grant 90-1112 from the Michigan Oil and Gas Association and by a Scholarship awarded to Mr Corseuil by CAPES, Ministry of Education-Brazil. The authors wish to thank Mark
Henry and Angela Lee, graduate students in the Environmental and Water Resources Engineering program at the University of Michigan at the time of this study, for their assistance in the experimental and analytical phases of the work. Dr Kevin P. Olmstead, a Postdoctoral Research Associate in the EWRE program, provided helpful input for the experimental design phase of the work.

\section{REFERENCES}

Aamand J., Jørgensen C., Arvin E. and Jensen B. (1989) Microbial adaptation to degradation of hydrocarbons in polluted and unpolluted groundwater. J. Contam. Hydrol. 4, 299-312.

Alexander M. (1985) Biodegradation of organic chemicals. Envir. Sci. Technol. 19, 106-111.

Alvarez P. J, and Vogel T. M. (1991) Substrate interactions of benzene, toluene, and para-xylene during microbial degradation of pure cultures and mixed culture aquifer slurries. Appl. envir. Microbiol. 57, 2981-2985.

Arvin E., Jensen B. K. and Gunderssen A. T. (1989) Substrate interactions during aerobic biodegradation of benzene. Appl. envir. Microbiol. 55, 3221-3225.

Bauer J. E. and Capone D. G. (1988) Effects of co-occurring aromatic hydrocarbons on degradation of individual polycyclic aromatic hydrocarbons in marine sediment slurries. Appl. envir. Microbiol. 54, 1649-1655.

Corseuil X. H. (1992) Enhanced degradation of monoaromatic hydrocarbons in sandy aquifer materials by inoculation using biologically active carbon reactors. Ph.D. dissertation, The University of Michigan.

Corseuil X. C. and Weber W. J. Jr (1994) Potential biomass limitations on rates of degradation of monoaromatic hydrocarbons by inidgenous microbes in subsurface soils. Wat. Res. 28, 1415-1423.

Crawford R. C. and Mohn W. W. (1985) Removal of pentachlorophenol from soil using a Flavobacterium. Enzyme Microb. Technol. 7, 617-620.

Edgehill R. U. and Finn R. K. (1983) Microbial treatment of soil to remove pentachlorophenol. Appl. envir. Microbiol. 45, 1122-1125.

Harvey R. W., George L. H., Smith R. L. and LeBlanc D. R. (1989) Transport of microspheres and indigenous bacteria through a sandy aquifer: results of natural- and forced-gradient tracer experiments. Envir. Sci. Technol. 23, 51-55.

Lehtomäki M. and Niemelä S. (1975) Improving microbial degradation of oil in soil. Ambio 4, 126-129.

Li A. Y. L. and DiGiano F. A. (1983) Availability of sorbed substrate for microbial degradation on granular activated carbon. J. Wat. Pollut. Control Fed. 55, 392-399.

Matthess G., Pekdeger A. and Schroeter J. (1987) Persistence and transport of bacteria and viruses in groundwater-a conceptual evaluation. J. Contam. Hydrol. 2, 171-188.

McCarty P. L. (1985) Application of biological transformations in ground water. In Proceedings, Second International Conference on Groundwater Quality Research (Edited by Durham N. N. and Redelfs A.), Stillwater, Okla, pp. 6-11.

Nelson M. J. K., Montgomery S. O., O'Neil E. J. and Pritchard P. H. (1986) Aerobic metabolism of trichloroethylene by a bacterial isolate. Appl. envir. Microbiol. 52, 383-384.

Oldenhuis R. L., Kuijk L., Lammers A., Janssen D. B. and Withold B. (1989) Degradation of chlorinated and non-chlorinated aromatic solvents in soil suspensions by pure bacterial cultures. Appl. Microbiol. Biotechnol. 30, 211-217.

Ramadan M. A., El-Tayeb O. M. and Alexander M. (1990) Inoculum size as a factor limiting success of inoculation for biodegradation. Appl. envir. Microbiol. 56, 1392-1396. 
Weber W. J. Jr and Corseuil H. X. (1991) An engineering reactor approach to integrating physicochemical and biological processes for in-situ bioremediation of BTEX contaminated subsurface systems. In Environmental Engineering, Proceedings of the 1991 Specialty Conference of ASCE (Edited by Krenkel P. A.), Reno, Nev., pp. 191-197.

Weber W. J. Jr, Friedman L. D. and Bloom R. Jr (1970) Physicochemical treatment of wastewater. J. Wat. Pollut. Control Fed. 42, 83-99.
Weber W. J. Jr, Friedman L. D. and Bloom R. Jr (1973) Biologically extended physicochemical treatment. In Advances in Water Pollution Research (Edited by Jenkins S. H.). Pergamon Press, New York.

Zaldi B. R., Murakami and Alexander M. (1989) Predation and inhibitors in lake water affect the success of inoculation to enhance biodegradation of organic chemical. Envir. Sci. Technol. 23, 859-863. 